therapy, because of the great individual variation in response to all anticoagulant drugs, it is impossible to know whether the patient will need small or large maintenance doses. Regulation of dose has therefore to be by trial and error guided by the results of the blood tests. Thus it is a great advantage to use an anticoagulant whose action is rapid enough for any material change in dosage to be reflected in the prothrombin times the following day.

After the first few doses of maintenance therapy, and once the prothrombin time is in the required therapeutic range, it is rarely necessary to alter the daily maintenance dose of warfarin sodium by more than 1.5 to $2 \mathrm{mg}$. When the prothrombin time has been steady for three or four days it should be realized that a change in the daily dose of more than $0.5 \mathrm{mg}$. will lead after a few days to considerable fluctuations in the prothrombin times, owing to the cumulative effect of the drug. Once the approximate daily maintenance dose has been ascertained and the prothrombin times have been steady for three or four days, a good approximate guide to any further changes in the maintenance dose which may be necessary to maintain a steady unfluctuating prothrombin time is not to alter the amount of the dose by more than $5 \%$.

To determine the appropriate small variations in dose at this stage, bearing in mind the cumulative effect of anticoagulants, it is essential not just to consider the effect of a single dose on the prothrombin time the following day. A much clearer picture of the exact daily maintenance requirements of any anticoagulant will be obtained if the treatment is assessed over, say, a three-day period. By taking such a three-day period the full cumulative effect of small changes in dosage in the region of 5 to $10 \%$ can be readily seen and the exact daily maintenance requirements easily ascertained with a minimum of blood tests.

\section{Ease of Control}

Warfarin sodium is a remarkably easy drug to control, as the response to a given dose can almost invariably be reliably predicted. In this trial 25-mg., 10-mg., 5-mg., and 3-mg. tablets were made available. The $25-\mathrm{mg}$. tablet was used for initial dosage and the 10-mg., 5-mg., and 3-mg. tablets for maintenance therapy. For the initial doses of 35 to $50 \mathrm{mg}$. advised here, the 25-mg. tablet is unnecessary. To prescribe small variations in dose of the order of $5 \%$ the strength of tablet available is, however, of great importance. Indeed, to-day, with several good anticoagulants available, what makes one anticoagulant much easier to control than another is often the ease and convenience with which very small variations in dose may be prescribed.

The overall average maintenance dose of warfarin sodium is about $9 \mathrm{mg}$. and a $5 \%$ variation of this amount about $0.5 \mathrm{mg}$. In assessing the exact daily requirements, as mentioned earlier, it is essential to take a three-day period so that the full cumulative effect of the drug on the prothrombin times can be taken into account. For warfarin sodium one-half of a 3-mg. tablet, more or less, each threeday period, would give the necessary $0.5-\mathrm{mg}$. variation a day. A tablet strength exceeding $3 \mathrm{mg}$. makes it much more diffcult to prescribe small variations in dose. To cater for initial doses of 35 to $50 \mathrm{mg}$., and for those patients who need daily maintenance doses of $12 \mathrm{mg}$. or more, a second tablet of 5 to $6 \mathrm{mg}$. or so is necessary. With two such strengths of tablet $(3 \mathrm{mg}$. and $5 \mathrm{mg}$.) accurate assessment of dosage can be quickly and easily made. For long-term therapy a tablet strength of approximately $3 \mathrm{mg}$. is essential.

\section{Conclusions}

Warfarin sodium was used in the treatment of 175 patients with thrombo-embolic diseases. It is a rapidly acting drug, and $95 \%$ of all patients reached a therapeutic prothrombin time in 36 hours. With daily doses of the drug just sufficient to maintain a therapeutic prothrombin time the duration of action is approximately 36 hours. However, in large doses warfarin sodium has a very sustained effect, with a duration of action up to four to five days. It is important, therefore, to avoid large doses. The usually recommended initial dose of 60 to $75 \mathrm{mg}$. proved far too much in this series ; 35 to $50-\mathrm{mg}$. doses proved perfectly adequate for initial therapy, and it is inadvisable to exceed $50 \mathrm{mg}$. as an initial dose. The overall average maintenance dose was $9 \mathrm{mg}$., and $80 \%$ of all patients were maintained on daily doses between 5 and $15 \mathrm{mg}$.

Warfarin sodium proved extremely easy to control, and it probably ranks with phenindione as one of the two best anticoagulant drugs available for short-term therapy. Initial experience with warfarin sodium shows that it is also a very useful anticoagulant for long-term therapy. Great care must be taken in prescribing the anticoagulant to allow for the very definite cumulative effect of the drug. In this respect warfarin sodium resembles in its action that of phenylpropylhydroxycoumarin, which has proved a very reliable anticoagulant for long-term therapy.

To obtain the best results with warfarin sodium it is necessary to have available a strength of tablet with which to prescribe variations in dose of $0.5 \mathrm{mg}$. easily and quickly. It is considered that scored 3- and 5-mg. tablets would be ideal.

Thanks are due to Dr. Samuel M. Gordon, of Endo Laboratories Inc., New York, for his most helpful advice and for making available the various strengths of coumadin tablets which I have used, and also to Evans Medical Supplies Ltd. for supplying warfarin sodium (" marevan") in $3 \mathrm{mg}$. and $5 \mathrm{mg}$. strengths.

\section{REFERENCES}

Pollock, B. E. (1955). J. Amer. med. Ass., 159, 1094.

Shapiro. S. (1953). Anglology, 4, 380.

Wolff, (1956). Brit. med. J., 1, 1301. Proc. Mayo Clin., 28, 489 .

\section{STAPHYLOCOCCUS AUREUS TYPE 80 AND HUMAN INFECTIONS IN UGANDA}

\author{
BY
}

\section{R. S. F. HENNESSEY, C.M.G., M.D., F.R.C.P.I. Dip. Bact. \\ AND \\ R. A. MILES, A.M.I.L.T. \\ Wellcome Laboratories of Tropical Medicine, London}

The differentiation of cultures of staphylococci by phage-typing has contributed notably towards an understanding of the epidemiology of staphylococcal disease. As well as being of value in tracing infections to particular sources, the method has provided useful information about the distribution and spread of strains of different phage types. Studies of strains isolated from healthy persons and hospital patients have shown that some phage types occur more frequently than others in certain environments, while an association between phage type and antibiotic resistance has been widely observed.

The high prevalence of antibiotic-resistant strains of phage group III in hospital infections is of special clinical interest (Blair and Carr, 1953; Rountree, 1953; Jackson, Dowling, and Lepper, 1954 ; Knight and Holzer, 1954). Again, some phage types seem to spread readily, while others are associated with infections possessing distinctive features. Examples of these tendencies are the recovery of type 52A strains from 
hospital infections of newborn infants (Barber, Hayhoe, and Whitehead, 1949 ; Colbeck, 1949) and of type 71 strains from impetigo contagiosa (Spittlehouse, 1955; Parker, Tomlinson, and Williams, 1955 ; Barrow, 1955) and pemphigus neonatorum (Gillespie, Pope, and Simpson, 1957). Staphylococci of phage type 80 have recently been found in serious infections, often of an epidemic nature ; this report is concerned with the relatively high incidence of such strains in a series of cultures from Uganda.

Infections caused by Staphylococcus aureus type 80 were first encountered in Australia in 1954 (Rountree and Freeman, 1955 ; Clarke, McGeoch, and Sippe, 1956). Strains of this type were lysed by a phage adapted from typing phage $52 \mathrm{~A}$, the adapted phage being designated typing phage 80 . They have been isolated from an epidemic of furunculosis among hospital workers and from many outbreaks of neonatal infection in hospitals throughout Australia. Skin lesions were numerous and some infants developed pyothorax. Nearly all strains were penicillin-resistant and appeared to be of relatively high virulence.

Since 1955, type 80 strains have been identified in Europe. They have been observed in several extensive hospital outbreaks in Britain (Anderson and Williams, 1956). Ruys (1957) has remarked upon their prevalence in the Netherlands, where they have been recovered from a considerable proportion of infective conditions. As in Australia, the strains were generally penicillinresistant, and Bijlmer (1957) recovered them from some fatal infections.

In view of the association of type 80 staphylococci with virulent infections in Australia and Europe, it was of interest to find that about $40 \%$ of 248 strains recently sent to us from East Africa belonged to this type. The strains had been recovered from pus and other specimens collected from patients at two hospitals in Uganda. The results of phage-typing and antibiotic sensitivity tests are given below.

\section{Materials and Methods}

Between November, 1955, and March, 1957, batches of staphylococci isolated at the Central Laboratory, Kampala, were sent to us at intervals of a few months for study of their lysogenic properties. These strains, which were unselected, came from routine cultures of material collected in the wards and out-patient departments of two general hospitals at Kampala; one (Mulago Hospital) served Africans and the other (Nakasero Hospital) served mainly Asians and Europeans. Strains were tested for coagulase production in tubes with $1 / 5$ dilution of human plasma. Coagulase-positive strains were phage-typed by the method of Williams and Rippon (1952) and tested for antibiotic sensitivity on agar plates by means of " sentest " tablets.

\section{Phage-typing}

A total of 248 strains proved to be coagulase-positive. They all produced yellow pigment and were taken to be Staph. aureus. Table I gives the numbers of strains belong-

TABLE I.-Phage-typing of Strains of Staph. aureus from Two Kampala Hospitals

\begin{tabular}{|c|c|c|c|c|c|c|c|c|c|}
\hline & \multicolumn{2}{|c|}{ Group I } & \multirow{2}{*}{ 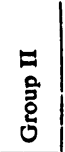 } & \multirow{2}{*}{$\begin{array}{l}\text { E } \\
\vdots \\
\vdots \\
0\end{array}$} & \multicolumn{3}{|c|}{ " Mixed" } & \multirow[b]{2}{*}{ 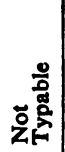 } & \multirow[b]{2}{*}{ Total } \\
\hline & $\stackrel{2}{2}$ & $\begin{array}{l}\text { 总 } \\
\text { ơ }\end{array}$ & & & 罜 & 景 & $\underset{I}{\text { 罗 }}$ & & \\
\hline $\begin{array}{l}\text { Mulago Hospital .. } \\
\text { Nakasero Hospital .. }\end{array}$ & $\begin{array}{l}73 \\
25\end{array}$ & $\begin{array}{l}23 \\
16\end{array}$ & $\begin{array}{l}13 \\
12\end{array}$ & $\begin{array}{l}22 \\
22\end{array}$ & $\begin{array}{r}19 \\
2\end{array}$ & $\begin{array}{l}1 \\
0\end{array}$ & $\begin{array}{l}1 \\
0\end{array}$ & $\begin{array}{r}9 \\
10\end{array}$ & $\begin{array}{r}161 \\
87\end{array}$ \\
\hline Total .. & $\begin{array}{l}98 \\
40 \%\end{array}$ & $\begin{array}{l}39 \\
15 \%\end{array}$ & $\begin{array}{l}25 \\
10 \%\end{array}$ & $\begin{array}{l}44 \\
18 \%\end{array}$ & $21 \%$ & & & $8 \%$ & 248 \\
\hline
\end{tabular}

ing to the various phage groups and to phage type 80 which were recovered from specimens received from each hospital.

The proportions of type 80 strains derived from Mulago and Nakasero Hospitals were thus $73 / 161(45 \%)$ and $25 / 87$ (29\%) respectively. Type 80 strains were by far the commonest single phage type in the whole series; as shown in the Chart, they were frequently recovered from all sources except "sundry specimens" (sputa, urines, blood cultures, swabs from the upper respiratory tract). They made up $45 \%$ of 103 strains from "deep" infections which included 80 abscesses (23 classed as "pyomyositis," 6 cases of osteomyelitis, and 4 of empyema); $48 \%$ of

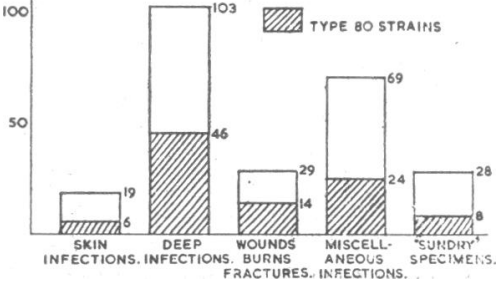

Proportions of type 80 strains among cultures from different sources.
29 strains from wounds, burns, and fractures; and $35 \%$ of 69 strains from miscellaneous pyogenic infections which could not be allocated to the "skin" or " deep " category on the clinical data.

The incidence of type 80 infections among patients of different races was $45 \%$ (73 out of 161) in Africans, $30 \%$ (10 out of 33 ) in Asians, and 28\% (15 out of 54) in Europeans.

When type 80 strains were tested for lysogenicity, it was found that 9 out of the 98 strains released phage which lysed the remaining strains of this type. Except for these nine strains, no other type 80 strain yielded phage which could be detected on any of the indicator strains used. A nontypable strain released a phage which formed plaques on all type 80 strains; strains which were made lysogenic with this phage became resistant to typing phage 80 .

\section{Antibiotic Sensitivity}

The results of tests for antibiotic sensitivity are given in Table II. The proportion of penicillin-resistant strains was highest among staphylococci of phage groups I (90\%) and III $(64 \%)$. Strains resistant to both penicillin and streptomycin were much more frequent in group I, where 41 strains $(30 \%)$ belonged to this category.

TABLE II.-Sensitivity of 248 Strains of Staph. aureus to Antibiotics*

\begin{tabular}{|c|c|c|c|c|c|c|c|c|}
\hline & \multirow{2}{*}{$\begin{array}{l}\text { No. of } \\
\text { Strains }\end{array}$} & \multicolumn{6}{|c|}{ No. of Strains Resistant to } & \multirow{2}{*}{$\begin{array}{l}\text { No. of Strains } \\
\text { Sensitive to } \\
\text { P S A T C E }\end{array}$} \\
\hline & & $\mathbf{P}$ & $\mathbf{S}$ & $\mathbf{A}$ & $\mathbf{T}$ & C & $\mathbf{E}$ & \\
\hline 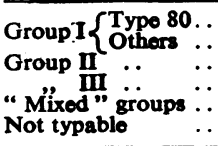 & $\begin{array}{l}98 \\
39 \\
25 \\
44 \\
23 \\
19\end{array}$ & $\begin{array}{r}95 \\
28 \\
2 \\
28 \\
3 \\
6\end{array}$ & $\begin{array}{r}30 \\
15 \\
0 \\
7 \\
0 \\
3\end{array}$ & $\begin{array}{l}3 \\
0 \\
0 \\
6 \\
0 \\
1\end{array}$ & $\begin{array}{l}3 \\
0 \\
0 \\
6 \\
0 \\
0\end{array}$ & $\begin{array}{l}0 \\
0 \\
0 \\
4 \\
0 \\
0\end{array}$ & $\begin{array}{l}\mathbf{0} \\
\mathbf{0} \\
\mathbf{0} \\
\mathbf{0} \\
\mathbf{0} \\
\mathbf{1}\end{array}$ & $\begin{array}{r}3 \\
10 \\
23 \\
16 \\
20 \\
9\end{array}$ \\
\hline Total & 248 & 162 & 55 & 10 & 9 & 4 & 1 & 81 \\
\hline
\end{tabular}
cycline. $\mathbf{C}=$ Chloramphenicol. $\mathrm{E}=$ Erythromycin.

Table II shows the extent of penicillin resistance in strains of each group and of type 80 . Resistance to both penicillin and streptomycin was present in $28 \%$ ( 27 out of 98 ) of type 80 strains.

\section{Discussion}

Information about the phage types of staphylococci which are responsible for human infections in tropical Africa seems to be lacking. This series of strains from Uganda is of interest in that the predominant phage type (type 80) is one which has displayed marked pathogenicity in Australia and Europe. Type 80 strains made up $40 \%$ of the series, the remainder showing a wide range of differing lytic patterns. Among the staphylococci of phage group I, which 
outnumbered those of group III by more than 3 to 1 , the proportion of type 80 strains was $\mathbf{7 2 \%}$.

Type 80 strains were associated with a variety of infective conditions, some of which may have been acquired in hospital. The proportion of type 80 strains among staphylococci recovered from different sources ranged from $32 \%$ (skin lesions) to $48 \%$ (wounds, burns, and fractures). There was no indication that type 80 infections occurred as part of a definite " outbreak"; between $20 \%$ and $60 \%$ of each of five batches of strains received over 17 months were of this type.

The high incidence of penicillin resistance among type 80 strains accords with experience elsewhere. These staphylococci, possessing a distinctive lytic pattern and a marked insensitivity to penicillin, seem to form a group of considerable pathogenic potentiality. From the lysogenic standpoint, the 98 strains classed as type 80 were not homogeneous, nine strains liberating a phage to which all the remaining type 80 strains were sensitive. It would appear that type 80 strains, like type 52A strains, possess properties which favour their growth and spread in man; further data relating to their prevalence among the patients and staff of hospitals in tropical Africa would be valuable.

\section{Summary}

Strains of Staph. aureus type 80 formed $40 \%$ of 248 cultures of coagulase-positive staphylococci recovered from patients suffering from various infective conditions in Uganda. Type 80 strains were by far the commonest phage type in this series, and nearly all $(97 \%)$ were penicillin-resistant. Strains of this type appear to be responsible for serious infections; their prevalence among hospital workers deserves study.

We are indebted to Dr. A. B. Raper and Dr. E. C. Buck for strains of staphylococci, and to Dr. R. E. O. Williams and Dr. Joan E. Rippon for typing phages and helpful information.

\section{REFERENCES}

Ancerson, E. S., and Williams, R. E. O. (1956). J. clin. Path., 9, 94 Barber, M., Hayhoe, F. G. J., and Whitehead, J. E. M. (1949). Lancet, 2,

Barrow, G. I. (1955). J. Hyg. (Lond.), 53, 495.

Bijlmer, J. (1957). Ned. T. Geneesk., 101, 222.

Blair, J. E., and Carr, M. (1953). J. infect. Dis., 93, 1.

Clarke, A. J. R., McGeoch, A. H., and Sippe, G. R. (1956). Med. J. Aust.,

Colbeck, J. C. (1949), Canad, med. Ass, J., 61, 557.

Gillespie, W. A., Pope, R. C., and Simpson, K. (1957). Brit. med. J., 1. 1044.

Jackson, G. G.. Dowling, H. F., and Lepper, M. H. (1954). J. Lab. clin. Med., 44, 29.

Knight, V., and Holzer, A. R. (1954). J. clin. Invest., 33, 1190

Parker, M. T.. Tomlinson, A. J. H., and Williams, R. E. O. (1955). J. Hyg. (Lond.), 53, 458 .

Rountree, P. M. (1953). Lancet, 1, 514

- and Freeman, B. M. (1955). Med. J. Aust., 2, 157.

Ruys, A. C. (1957). Ned. T. Geneesk., 101, 355.

Spittlehouse, K. E. (1955). Lancet, 2, 378.

Williams, R. E. O., and Rippon, J. E. (1952). J. Hyg. (Lond.), 50, 320.

Speaking at the conference of the National Society for Clean Air on October 1, the Minister of Housing and Local Government, Mr. HENRY BROOKE, said that on the industrial side we ought to see a substantial improvement within the next five years or so. The period allowed by the Clean Air Act for alterations to plant expired in the middle of 1963. During this time all the necessary improvements to furnaces and boilers would have to be carried out-the fitting of mechanical stokers, and the provision of instruments for observing and checking smoke. There ought also to be a steady growth in the fitting of dust and grit arrestors to furnaces. In the processes which came under the Alkali Act there should also be improvements coming along by then. For instance, in the gas and electricity and pottery industries the process of shutting down older works would have gone yet a stage further; and it was the older works which so often were responsible for the most smoke.

\section{Medical Memoranda}

\section{Arteriovenous Fistula Following Blunt Trauma}

Recently we had occasion to treat an arteriovenous fistula which seemingly resulted from a non-penetrating wound and had no features to suggest a congenital origin. A review of the modern literature failed to reveal a similar fistula following trauma by a blunt instrument which did not penetrate the tissues.

Post-traumatic arteriovenous fistulae and false aneurysms are a frequent complication of penetrating wounds in war. In civilian life congenital arteriovenous fistulae are often encountered, but an arteriovenous fistula or false aneurysm following a non-penetrating wound is a rarity. The case under discussion represents another form of aetiology of arteriovenous fistulae which is uncommon enough to be of interest to others.

\section{CASE REPORT}

A man aged 21 was referred because of a history that he. had been struck on the left temple by a hockey ball. $\mathrm{He}$ was not rendered unconscious, but noted the immediate formation of a swelling at the area of impact, which in three to four hours' time had assumed the size of half a goose's egg. The skin was not broken nor was there any bleeding. On the evening of his injury he noticed a "buzzing" sensation just in front of the left ear. Within the next few days the swelling disappeared, but he continued to be aware of a whirring sensation in the area of trauma, noted when recumbent with the head turned so that the left side was down. It was only the persistence of this annoying buzzing in front of the ear for four months that led him to seek medical attention. Close questioning failed to disclose any history of previous penetrating injury in the left temple area or any skin lesion such as a capillary naevus or angioma.

On examination the pulse rate and volume were normal ; blood pressure $130 / 80 \mathrm{~mm}$. $\mathrm{Hg}$. The significant physical findings were limited to the left temporal area, where there were several conspicuous subcutaneous veins anterior to the ear. Light palpation disclosed a systolic thrill, and on auscultation there was a continuous murmur with a crescendo in systole. Firm pressure upon the superficial temporal artery abolished the bruit; lighter pressure over the dilated veins caused marked engorgement of the veins of the scalp, and the bruit again disappeared. In view of the history and findings a diagnosis of post-traumatic arteriovenous fistula of the superficial temporal artery and vein was made, and at operation the superficial temporal artery and vein were exposed and found to have a fistulous communication. Accordingly a quadruple ligation was performed with excision of included vein, artery, and fistula. Recovery was uneventful and the patient has noted no further symptoms.

\section{COMMENT}

The pathogenesis of the fistula presents the point of major interest in this case. The patient absolutely denied any abnormal prominence of the veins of his temple, peculiar vibrations, or whirring prior to the traumatic episode. In fact, there was nothing to suggest that he might have had a small arteriovenous fistula which was enlarged by the blow. It seems most likely that the two vessels lying in close proximity must have been ruptured partially by the severe force, forming a communicating haematoma between them. A vascular channel subsequently developed and remained patent after resorption of the confined haematoma. Owing to the anatomy of the temporal region the haematoma was enclosed in a small space limited by the epicranial aponeurosis and its attachments to the zygomatic arch. There was little chance of dissection of the extravascular blood such as would be allowed in the areolar tissues surrounding vessels in most parts of the body. 